\title{
((D)]
}

\section{IMPORTÂNCIA DA ERGONOMIA NA CONCEPÇÃO DE MÓVEIS ESTOFADOS - SOFÁS}

\section{IMPORTANCE OF ERGONOMICS INFURNITURE DESIGN UP HOLSTERY-SOFAS}

\author{
FIALHO, Patrícia Bhering (1) \\ SOUZA, Amaury Paulo (2) \\ MINETTE, Luciano José (3)
}

(1) Centro Federal de Educação, Professora, Doutorado

e-mail: patricia@curvelo.cefetmg.br

(2) Universidade Federal de Viçosa, Professor, PhD

e-mail: amaury@ufv.br

(3) Universidade Federal de Viçosa, Professor, Doutorado

e-mail: minetti@ufv.br

\begin{abstract}
RESUMO
Este trabalho tem como objetivo realizar um estudo bibliográfico sobre o produto "sofá" e os diferentes fatores que interferem no projeto desse móvel, como conhecimento técnico sobre seus componentes, mercado moveleiro, normas técnicas, além de enfatizar a importância da ergonomia na sua concepção.

Palavras-chave: produto; sofás, ergonomia

\section{ABSTRACT}

This study aims to conduct a literature research about the product "sofa" and the various factors that interfere in design of this furniture, like technical knowledge about its components, furniture market, technical norms and also emphasize the importance of ergonomics in its design.
\end{abstract}

Keywords: product; sofas, ergonomics.

\section{INTRODUÇÃO}

$\mathrm{Na}$ era da globalização, a competitividade e a dinâmica dos mercados são fatos concretos. No setor moveleiro, esse cenário não é diferente. Um dos mecanismos 


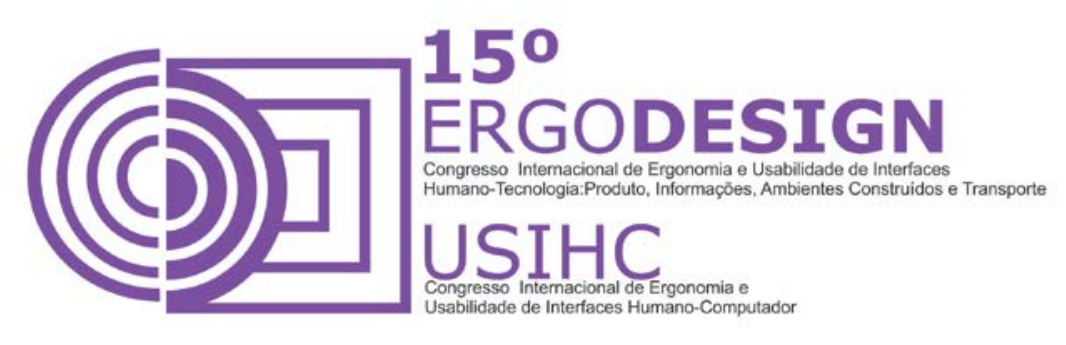

utilizados para a permanência e o crescimento desse segmento é a busca constante pela qualidade.

Segundo IIDA (1990), todos os produtos, sejam eles grandes ou pequenos, simples ou complexos, destinam-se a satisfazer certas necessidades humanas. Então, para que esses produtos funcionem bem em suas interações com o usuário ou consumidores, devem ter as seguintes características básicas:

- Qualidade técnica - é a parte que faz funcionar o produto, do ponto de vista mecânico, elétrico, eletrônico ou químico, transformando uma forma de energia em outra, ou realizando funções como cortes, soldas, dobragem e outras.

- Qualidade ergonômica - a qualidade ergonômica do produto inclui a facilidade de manuseio a adaptação antropométrica, o fornecimento claro de informações, as compatibilidades de movimentos e demais itens de conforto e segurança.

- Qualidade estética - a qualidade estética envolve a combinação de formas, cores, uso de materiais, texturas e cores, para que os produtos sejam visualmente agradáveis.

$\mathrm{Na}$ definição dessas qualidades, há também um forte componente econômico e de preferência dos consumidores. Muitas vezes, os fabricantes preferem alterar os aspectos estéticos e ergonômicos dos produtos por questões mercadológicas, porque as qualidades técnicas não são tão visíveis ao consumidor e também são de difícil modificação. Entretanto, existem também muitos casos de produtos que são tecnicamente bem resolvidos, mas fica difícil dotá-los depois das qualidades ergonômicas e estéticas.

Entre os móveis domésticos, destacam-se os sofás, presentes na maioria dos lares brasileiros. Apesar da sua importância no cotidiano das pessoas, verifica-se que muitos apresentam inadequações ergonômicas que podem afetar a saúde e o conforto do usuário. Além disso, pouco se conhece no meio acadêmico sobre o projeto e produção desses móveis.

Dessa forma, escolheu-se como objetivo deste trabalho realizar um estudo bibliográfico sobre o produto "sofá" e os diferentes fatores que interferem no projeto desse móvel como conhecimento técnico sobre seus componentes, mercado moveleiro, normas técnicas, além de enfatizar a importância da ergonomia na sua concepção.

\section{MÓVEIS}

O móvel possui diversas especificidades na vida cotidiana das pessoas, como:

- Hierarquização social. Segundo Ribeiro (2008), as pessoas utilizam-se dos objetos como forma de emitir uma mensagem aos seus grupos de referência buscando o enquadramento em um determinado grupo ou como forma de diferenciarse perante os demais. No caso dos móveis como as cadeiras, por exemplo, Lanutti et al. (2009) citam que a "cadeira é sinônimo de posição privilegiada ou de autoridade." Historicamente, poder e cadeira sempre estiveram juntos. Segundo Paoliello (2008), a cadeira é utilizada desde a época dos faraós, que, ao se sentarem em seus tronos, 


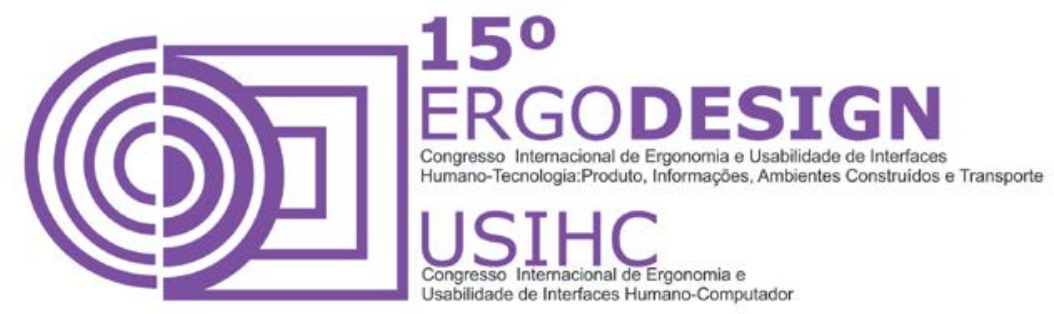

denotavam a sua origem divina. Outro exemplo são as cadeiras de escritório, que são diferenciadas conforme a relevância do profissional na empresa, como a "cadeira secretária", que possui encosto menor ao ser comparado com a "cadeira do gerente".

- Simbolismo e afetividade. O móvel é um elemento simbólico. Ele transmite as características de seus usuários como hábitos, costumes e sentimentos. Muitos são passados por gerações ou são associados a acontecimentos vividos.

- Socialização. Segundo Jordan e Tiger (2001, 2002 apud SILVA, E., 2003), "O prazer social é obtido pela interação com outros, isto é, com produtos que tenham, como consequência, a reunião, o agrupamento de pessoas." Diante disso, pode-se citar, como exemplo, a reunião familiar em volta de uma mesa, a acomodação de visitantes nos estofados da sala de estar etc.

- Praticidade: o móvel serve como objeto de auxílio a inúmeras atividades do cotidiano, como o acondicionamento de produtos, sustentação de pessoas (cadeira, cama etc), entre outros. Além disso, com a diminuição dos espaços das habitações contemporâneas o móvel serve no aproveitamento de espaços, oferecendo multifuncionalidades.

- Estética: o significado mais usual para o conceito de estética está relacionado ao belo, agradável, feio, harmonioso etc (BOMFIM, 1997 apud SILVA, E., 2003). Dessa forma, o móvel pode tornar-se um elemento estético na medida em que ele causa sensações e percepções nos seus usuários de forma a ser diferenciado de outros com a mesma função, pela agregação de elementos (adornos, texturas, materiais, formas, dentre outros).

- Estilo de vida: o móvel é um artefato que transmite modos de vida, como as mesas baixas utilizadas na cultura japonesa para a alimentação.

- Diferenciador de espaços: os móveis podem ser utilizados como elemento de organização do espaço arquitetônico. Por eles podem ser identificadas atividades desenvolvidas em determinados espaços. Como exemplo, ao visualizar uma cama em um cômodo, conclui-se que aquele espaço é para atividades de repouso.

- Prazer fisiológico: segundo Jordan e Tiger (2001, 2002 apud SILVA, E., 2003), o prazer fisiológico "deriva das sensações de toque, cheiro e sensualidade". Pode-se citar, como exemplo, o prazer gerado ao sentar-se sobre um estofado com tecido macio.

- Prazer psicológico: Segundo a Jordan e Tiger (2001, 2002 apud SILVA, E., 2003), o prazer psicológico está relacionado à "satisfação sentida quando uma tarefa é concluída com sucesso. O prazer também vem da extensão a qual o produto faz a tarefa mais prazerosa (...)". Isto acontece quando um móvel auxilia na conclusão de uma atividade.

- Conforto: lida (2005) cita o conforto como uma manifestação do usuário, de forma subjetiva, uma vez que, dificilmente, pode ser quantificado em números, mas, apenas, qualificado ou classificado.

Segundo análise do Instituto de Pesquisas DUE e a Central da Excelência Moveleira (2007, apud SEBRAE, 2008) sobre a importância das pesquisas de comportamento do 


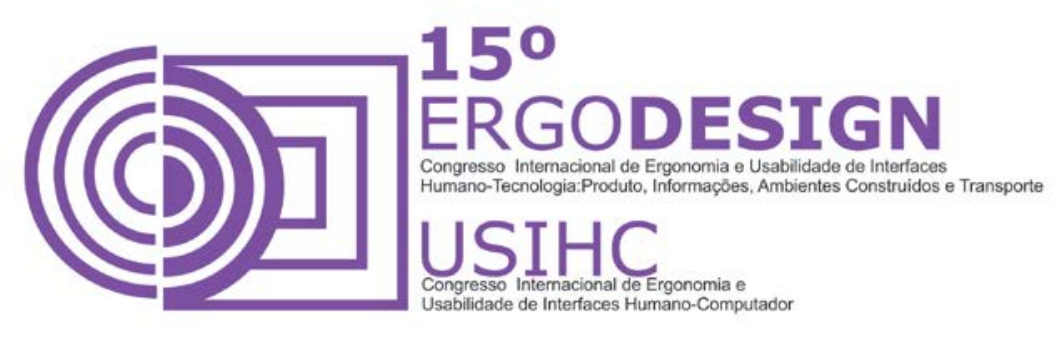

consumidor, verificou-se que os consumidores de diversos níveis sócio-econômicos possuem três valores essenciais e independentes:

- Praticidade e eficiência.

- Conforto.

- Beleza e harmonia.

O móvel que, antigamente, era comprado para ter durabilidade, passando de geração a geração, atualmente, acaba sendo trocado por mais vezes, para adequar-se as tendências de design e atender as exigências de espaço no imóvel e das novas tecnologias, como, por exemplo, comportar eletroeletrônicos que constantemente apresentam inovações de tamanho, modelos e funções.

Cabe ressaltar as mudanças culturais decorrentes da globalização, como as camas Box, muito utilizadas pelos americanos, que se popularizaram no Brasil, nos últimos anos.

Outro fator que tem interferido na compra de móveis é a durabilidade. Segundo Ribeiro (2008), a durabilidade dos materiais que compõem os móveis está sendo estrategicamente determinada pelo fabricante, de forma que o consumidor do móvel tenha a necessidade de voltar à loja para adquirir um novo bem, em curto e médio tempo.

Nos últimos anos, a aquisição de móveis tornou-se mais facilitada pelas classes sociais mais baixas. Esse fato pode ter sido impulsionado por diversos fatores como a estabilidade econômica, o aumento dasconcessões de crédito e os financiamentos e a diminuição das taxas de impostos.

Destaca-se, ainda, o aumento da compra de móveis relacionada a maior oferta de habitação no mercado nacional, onde a compra implica na necessidade de mobiliá-lo. Além de estimular o aumento na aquisição de móveis, notou-se que a construção civil também tem influenciado nas transformações da configuração dos móveis.

As transformações advêm da constante redução dos espaços, sobretudo nas cidades grandes e nas habitações voltadas às classes de renda mais baixa, de forma que os móveis sejam em menor número e de maior praticidade (SEBRAE, 2008).

Em 2013, indústria nacional de móveis produziu 476,2 milhões de peças acabadas, representando um aumento de 3,4\% comparado ao ano de 2012. Entre os anos de 2009 a 2013, houve crescimento de 28,7\%, demonstrando alta média de 6,5\% ao ano (INSTITUTO DE ESTUDOS E MARKETING INDUSTRIAL, 2014).

\section{MÓVEIS ESTOFADOS - SOFÁS}

A norma NBR 15164/2004 define sofá estofado como "móvel estofado de um ou dois lugares, composto de assento e encosto, com ou sem braço".

De forma geral, o processo de produção dos móveis estofados possui característica artesanal, com intensivo uso de mão-de-obra e de máquinas tradicionais.

No ano de 2013 , os estofados representaram $10,7 \%$ do total da produção moveleira do Brasil. (IEMI, 2014) 


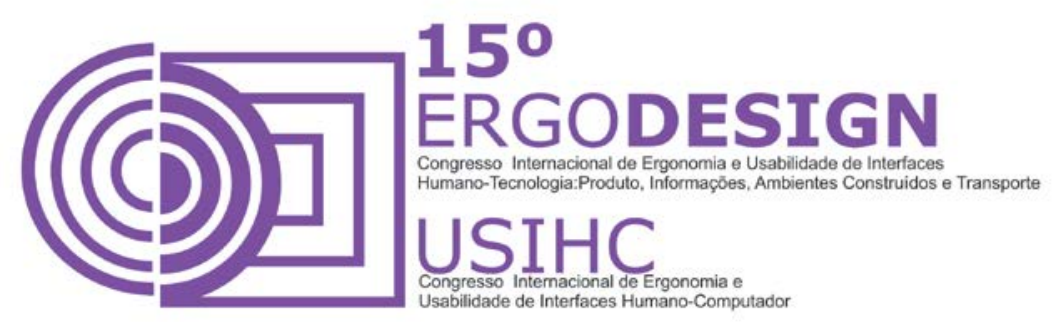

Quanto às matérias-primas utilizadas nas estruturas internas dos estofados, merece destaque a madeira maciça, embora se observa inovações de materiais, como as estruturas em aço galvanizado, que proporcionam, dentre outros fatores, maior leveza, imunidade a ataque de insetos e uniformidade, mas com a desvantagem de ter seu custo mais elevado.

De forma geral um estofado é composto pelos seguintes elementos:

- Apoia-braço (braço): a NBR 15164/2004 define o como "peça destinada ao apoio do antebraço e do cotovelo do usuário". Em geral, o apoia-braço é composto por uma estrutura de madeira ou de chapas de madeira reconstituída e espuma, podendo ter diferentes configurações que variam conforme o modelo do móvel.

- Assento: a NBR 15164/2004 define o como "superfície aproximadamente horizontal, destinada a que os usuários sentem, podendo ser composta de uma ou mais peças". O assento pode ser composto por grandes almofadas soltas ou por uma base fixa acoplada à estrutura. São formadas por espumas ou por conjunto de espuma e fibra siliconizada. Alguns modelos apresentam mola.

- Encosto: a NBR 15164/2004 define o como "superfície destinada ao apoio das costas do usuário". O encosto pode ser acoplado à estrutura ou composto por almofadas soltas. O seu enchimento pode ser de espumas ou por conjunto de espuma e fibra siliconizada, por espumas trituradas e flocadas.

- Percinta: a NBR 15164/2004 a define como "cinta elástica que tem como função formar um plano para a base do material do estofamento do assento e/ou encosto". As percintas utilizadas nos sofás estofados são formadas por borrachas (pneus) ou por faixas elásticas. O posicionamento das percintas pode ser em tramas retas perpendiculares $\left(90^{\circ}\right)$ ou compostas por tramas retas perpendiculares, associadas a outras, acopladas na diagonal $\left(45^{\circ}\right)$ para conferir maior resistência ao assento.

- Espumas de poliuretano: são definidas pela norma NBR 15164/2004 como "material químico ou fisicamente expandido, à base de poliuretano". As espumas conferem maciez e flexibilidade ao móvel. Cada parte do estofado é composto por espumas com diferentes características (densidade e espessura, flocada, inteira), que variam de acordo com as especificidades dos locais nos quais serão aplicadas. O assento, por ser um local com maior pressão, requeruma espuma com densidade superior do que a espuma utilizada no encosto.

- Mola: é definida pela NBR 15164/2004 como "material, normalmente metálico e na forma de espiral, capaz de acumular energia elástica". As molas estão presentes em alguns modelos, sua função é dar apoio e resistir as pressões nos assentos, junto com as percintas.

- Pé: "parte inferior de uma peça que sustenta, a partir do solo, o corpo do móvel" (SENAI RS, 1994). Podem ser de metal, madeira ou plástico.

- Revestimentos: os revestimentos podem ser sintéticos ou naturais, como tecidos, couros etc.

- Acessórios: possuem a função de complementarem o móvel. Os principais materiais dos acessórios nos estofados são os metais, as madeiras maciças e as 


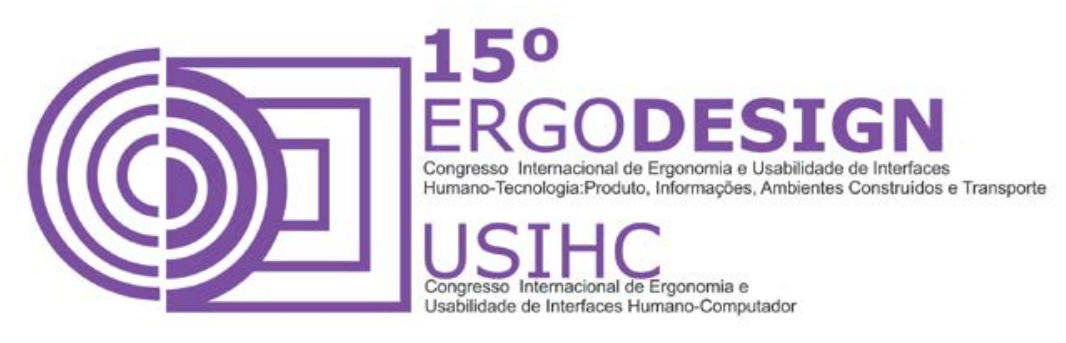

chapas reconstituídas, utilizados nos pés e em detalhes de revestimentos. Muitos acessórios são utilizados apenas como elementos estéticos, outros podem dar maior funcionalidade ao móvel. Sua disposição e características variam conforme o modelo do estofado.

A Figura 1 é representativa dos elementos básicos externos e internos que compõem os estofados.

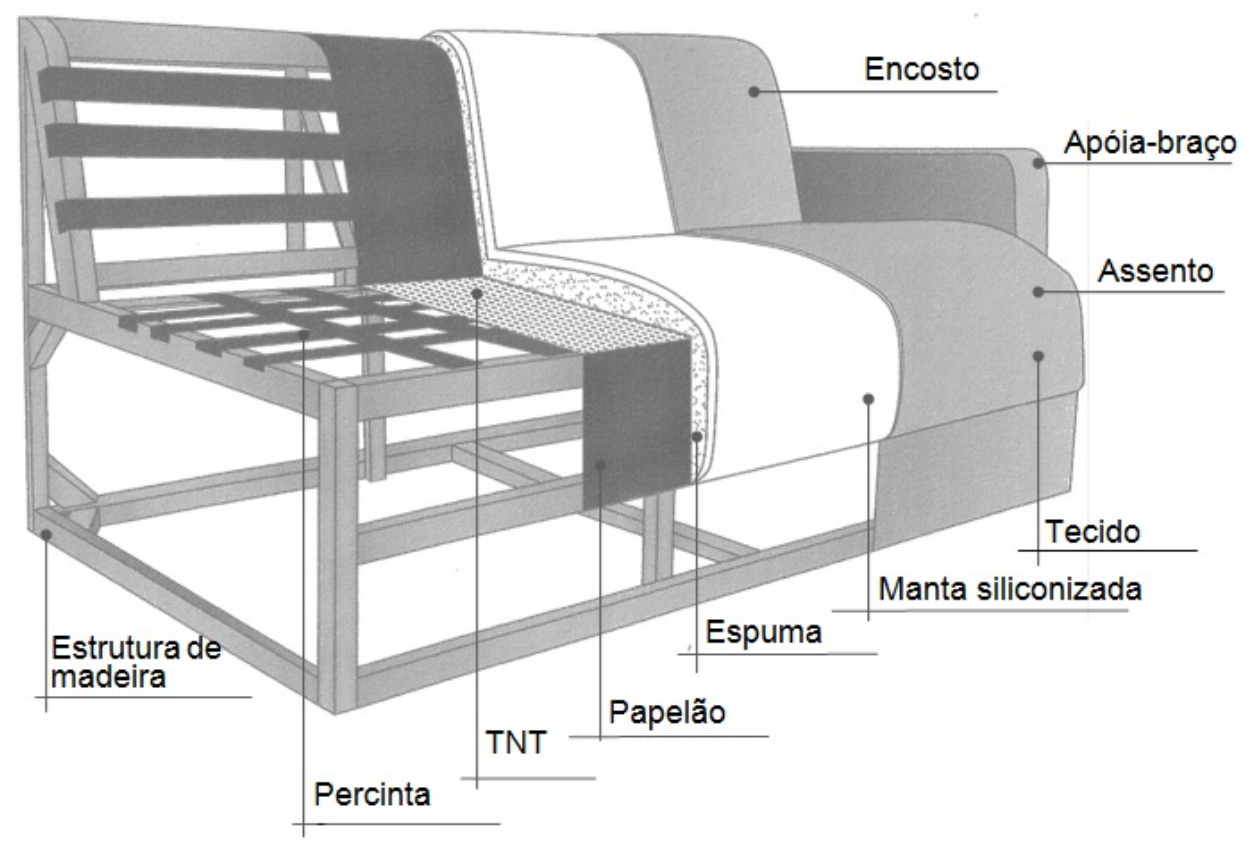

Figura 1 - Representação dos elementos básicos externos e internos que compõem a estrutura dos sofás estofados, baseados nas referências bibliográficas.

Com o propósito de ilustração, a Figura 1 é meramente representativa de um modelo básico de um sofá estofado. Alguns itens, como molas e acessórios podem ser ou não acoplados ao móvel. O papelão e os tecidos não tecidos (TNT) também apresentam variações nos locais de aplicação, conforme o modelo do estofado.

Nos últimos anos verifica-se no mercado um aumento na oferta de modelos de estofados. Além de muitos apresentarem profundidades de assento maiores, proporcionam a possibilidade de aumento do mesmo, por meio de mecanismos de ajuste extensível. Existem, também, os modelos de estofados "Chaise", que possuem profundidades maiores; entretanto, estes estofados apresentaram assentos fixos e não são extensíveis, conforme representação da Figura 2. 

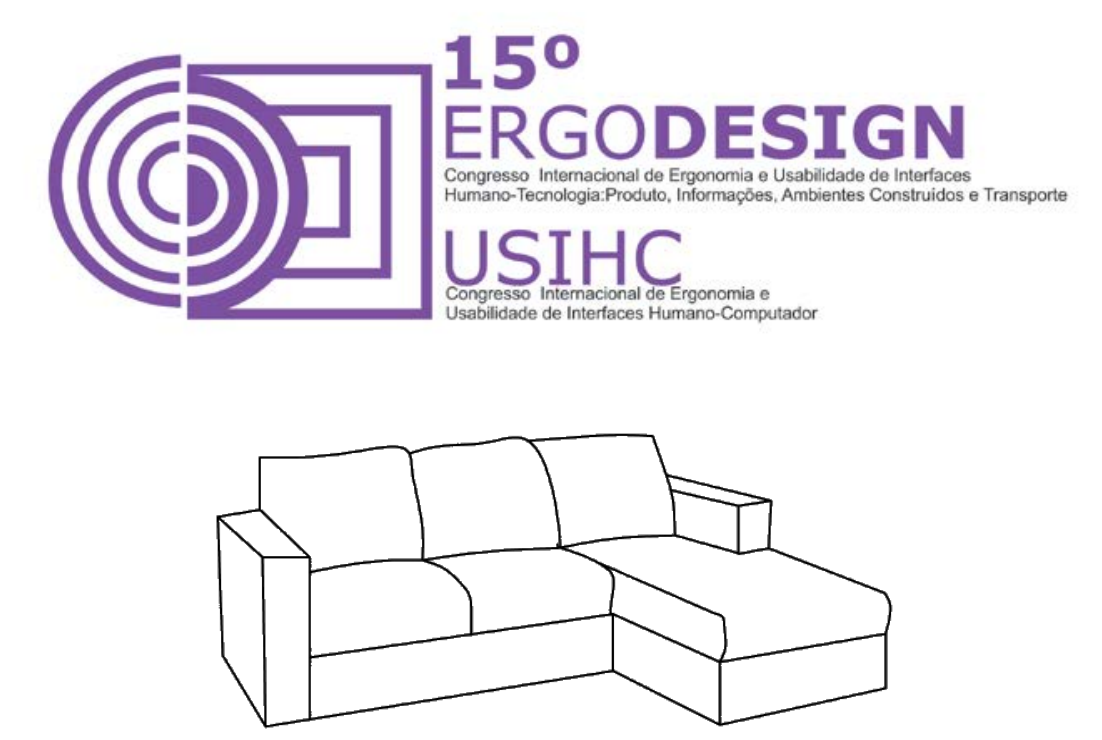

Figura 2 - Representação de um estofado com "Chaise"

Além das evoluções nas dimensões dos assentos, muitos sofás apresentam possibilidade de modificação na inclinação dos encostos, conforme a representação do exemplo da Figura 3.

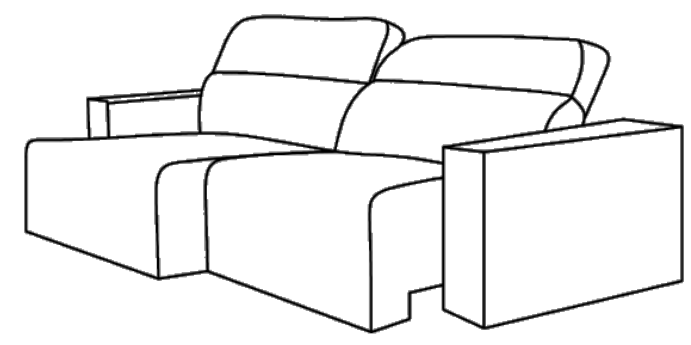

Figura 3 - Representaçãode um estofado com estofado retrátil e modificação da inclinação do encosto e assento extensível

O dimensionamento dos estofados depende de vários fatores, como:

- Função a ser exercitada dentro do ambiente (relaxamento, atividades visuais, como assistir televisão ou de leitura).

- Dimensões antropométricas de seus usuários.

- Perfil dos usuários. Como exemplo, pessoas idosas necessitam de estofado mais alto e com pouca deformação no assento para ter maior facilidade ao sentar-se e levantar-se.

- Dimensão do espaço onde será alocado.

\section{ERGONOMIA}

A ergonomia é definida pela Associação Internacional de Ergonomia (2000 apud Associação Brasileira de Ergonomia) como: "uma disciplina científica relacionada ao entendimento das interações entre os seres humanos e outros elementos ou sistemas, e à aplicação de teorias, princípios, dados e métodos a projetos a fim de otimizar o bem estar humano e o desempenho global do sistema".

Para Couto (1995), a intervenção da ergonomia se faz por meio de três situações: 


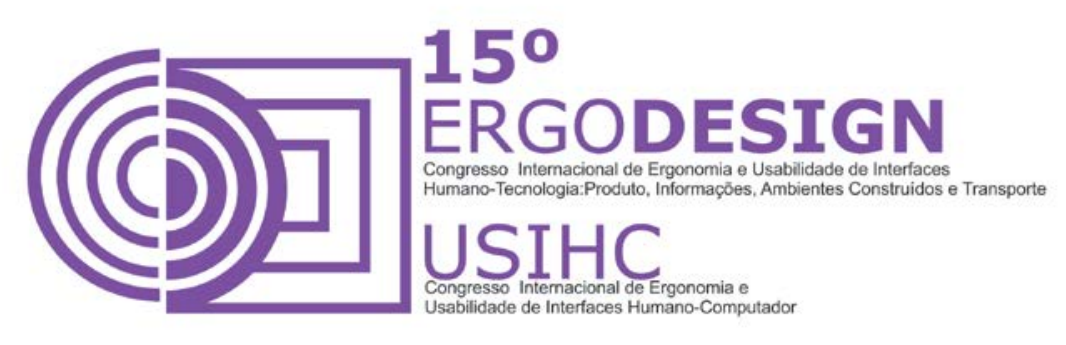

a) Ergonomia de concepção: ocorre quando a contribuição ergonômica se faz durante a fase inicial de projeto do produto, da máquina ou do ambiente.

b) Ergonomia de correção: é aplicada em situações reais já existentes, com a finalidade de resolver problemas que se refletem na segurança, na fadiga excessiva, em doenças do trabalhador ou na quantidade e qualidade da produção.

c) Ergonomia de conscientização: consiste na conscientização do operador, através de cursos de treinamento e frequentes reciclagens, ensinando-o a trabalhar de forma segura, reconhecendo os fatores de riscos que podem surgir a qualquer momento, no ambiente de trabalho.

De acordo com Mafra e Vidal (2002), a atuação da ergonomia sempre acarreta inovação, seja ela de práticas, de processo, de produto, ou de representações sociais.

\section{ERGONOMIA DOS PRODUTOS NA INDÚSTRIA MOVELEIRA}

Segundo Sell (1997 apud SILVA et al, 1998), no desenvolvimento de um projeto de um produto os envolvidos devem basear-se por determinadas frentes de ação ergonômica, orientadas em nível de priorização:

1. Dimensionamento, forma, alocação, estruturas e ajustes.

2. Funcionamento da tarefa de trabalho, forças, movimento e informações e emissão de agentes adversos.

3. O tipo, a forma de emissão, a quantidade e a decodificação das informações.

4. Detalhes construtivos do produto (indicações, material, cor e acabamento superficial) e dos elementos de contato (comandos, meios de informação e pontos de pega).

5. Dispositivos de segurança.

Da união dos conceitos de design e da ergonomia surgiu o Ergodesign, que de acordo com Mont'Alvão (2007), é uma abordagem sem barreiras, interativa e interdisciplinar, que garante uma transformação direta de dados ergonômicos no processo de projeto e estimula a suave interação da "teoria na prática".

Segundo Mendonça e Almeida Jr. (2007), o desenvolvimento de produtos, que atendem às questões ergonômicas necessita, do envolvimento de profissionais de diversas áreas de conhecimento para garantir um embasamento técnico-científico que excede a visão do designer de produto.

O conforto, apesar do seu caráter subjetivo, tem que ser considerado na concepção ergonômica de móveis; podendo ser aplicado, como exemplo, na escolha de revestimentos adequados ao uso e configurações mais anatômicas e adaptadas aos usuários.

Outro fator relevante para a ergonomia é a usabilidade, sendo descrita pela norma ISO DIS 9241-11 (1998, apud DIAS, 2000), como "a capacidade de um produto ser usado por usuários específicos para atingir objetivos específicos com eficácia, eficiência e satisfação, em um contexto específico de uso". 


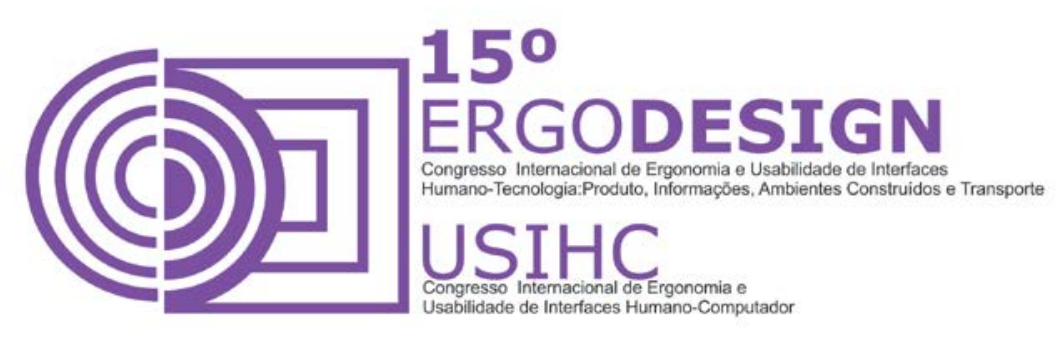

De acordo com Villarouco e Andreto (2008), a usabilidade "trata da adequação entre o produto e as tarefas a cujo desempenho ele se destina, da adequação com o usuário que o utilizará e ao contexto em que será usado".

Quando o projeto de um móvel não leva em consideração a ergonomia, o usuário pode adotar posturas inadequadas ao utilizar o produto. Para Couto (1996), além da fadiga muscular imediata, há diversos efeitos que se verificarão em longo prazo, como a formação de edemas, varizes, problemas nas articulações e, especialmente, na coluna vertebral.

A fabricação de um estofado ou qualquer outro móvel deve englobar não somente a estética e a funcionalidade, mas, também, os aspectos que poderão por em risco a integridade física e a saúde do consumidor. Os riscos de acidentes provocados pela não conformidade ergonômica, associados ao uso funcional ou não funcional do mobiliário, devem ser considerados nos critérios de avaliação. Um estofado que apresente quinas "vivas", arestas e bordas cortantes, pode causar pequenos acidentes aos usuários, como cortes e hematomas. Os acidentes ao se levantar ou sentar-se, devido às inadequações antropométricas, também devem ser considerados e evitados. A estabilidade é também uma característica indispensável ao produto, de forma a evitar desequilíbrios e danos físicos aos usuários dos móveis.

Outro fator importante nessa questão é a utilização de produtos químicos na etapa de acabamento dos móveis, como vernizes, seladores, solventes, tintas e outros derivados químicos, que podem exalar odores, durante certo tempo, podendo causar alergias aos usuários mais sensíveis.

\section{NORMAS TÉCNICAS}

A utilização de normas técnicas é um importante instrumento de melhoria na qualidade técnica e ergonômica de um produto. Segundo Bucich (2004), as normas técnicas ligadas a ergonomia tratam de temas amplos como os procedimentos de fabricação, regras direcionadas a postos de trabalho, características de produtos etc.

No Brasil, existem poucas normas técnicas direcionadas aos móveis domésticos. Atualmente, estão em vigor as normas NBR 15164/2004 - Móveis Estofados - Sofás, NBR 13918/2000 - Berços infantis e as normas NBR 14033/1998 e NBR 14034/1998 Móveis de cozinha. Tais normas, no entanto, não têm, como foco especifico, a adequação ergonômica.

Nos últimos anos, houve um esforço das entidadesresponsáveis pela elaboração de normas em estabelecer parâmetros de avaliação da conformidade, tornado de caráter compulsório para a avaliação de diversos produtos; os móveis, no entanto, não foram contemplados.

Segundo Garcia e Motta (2007), a carência de normas específicas acarreta problemas para o setor moveleiro, uma vez que as empresas direcionadas ao mercado de massa produzem com o mínimo de custos. Utilizam muitas vezes, materiais inadequados e de baixa qualidade, gerando reclamações nos órgãos de defesa do consumidor, devido à falta de qualidade do produto final.

No Brasil, até 2014 não havia uma prática efetiva de avaliação da conformidade de móveis. São poucos os laboratórios acreditados junto ao Instituto Nacional de 


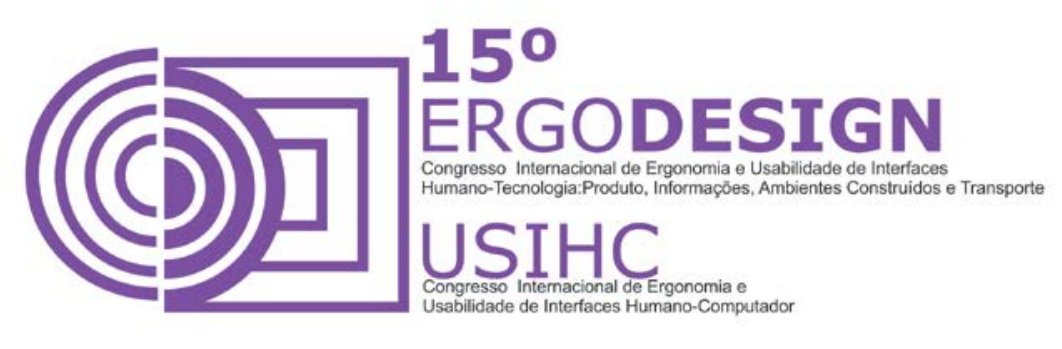

Metrologia, Normalização e Qualidade Industrial - INMETRO. Estes estão localizados no Rio de Janeiro, Minas Gerais, Rio Grande do Sul, Distrito Federal e São Paulo, em sua maioria, dedicando-se a realização de testes em móveis de escritórios, não priorizando os móveis domésticos. A única instituição acreditada pelo INMETRO que realiza testes em móveis estofados seguindo instruções normativas da ABNT é o Centro Tecnológico do Mobiliário (SENAI/CETEMO); localizado no Rio Grande do Sul, o que dificulta a avaliação desse tipo de móvel, devido à distância do laboratório aos diversos pólos moveleiros dentro do território brasileiro.

Além da necessidade de elaboração e difusão de normas técnicas ergonômicas para o setor moveleiro, é necessário o estabelecimento de novas normas ligadas às questões ambientais, com restrição ao uso de alguns produtos, formas de descarte e meios de reciclagem, tornando-se uma barreira aos produtos de baixa qualidade.

\section{CONSIDERAÇÕES FINAIS}

A partir da pesquisa bibliográfica realizada, verifica-se que apesar da grande interação que os móveis estofados - sofás possuem no cotidiano das pessoas, nota-se, que estudos voltados a melhoria desse produto ainda são escassos. A norma brasileira enfatiza aspectos técnicos de segurança e estabilidade, com pouco enfoque a ergonomia.

A "qualidade ergonômica" dentro dos seus princípios básicos, como a segurança, a funcionalidade, o bem-estar e a satisfação do ser humano, demonstra soluções práticas para o desenvolvimento de estofados que sejam adaptados a seus usuários e adequados a sua utilização diária.

\section{REFERÊNCIAS BIBLIOGRÁFICAS}

ASSOCIAÇÃOBRASILEIRA DE ERGONOMIA - ABERGO. O que é ergonomia. Disponível em: <http://www.abergo.org.br/internas.php?pg=o_que_e_ergonomia>. Acesso em: 16 out. 2011.

ASSOCIAÇÃO BRASILEIRA DE NORMAS TÉCNICAS. NBR 15164: Móveis estofados - sofás. Rio de Janeiro, 2004.

BUCICH C. A imposição da regra na produção industrial: Ergonomia nos processos de normalização e certificação. Ação ergonômica, v. 2, n.1, 2004. p. 29 - 46.

COUTO, H. A. Ergonomia aplicada ao trabalho: o manual técnico da máquina humana. Belo Horizonte: Ergo, 1995.1 v. 353p.

COUTO, H. A. Ergonomia aplicada ao trabalho: o manual técnico da máquina humana. Belo Horizonte: Ergo, 1996. 2 v. 383 p.

DIAS, C. Avaliação de usabilidade: conceitos e métodos. UnB. 2000. 13 p. Disponível em: <www.puccampinas.edu.br/ceatec/revista_eletronica/Segunda_edicao/Artigo_02/avaliacao de_Usabilidade.PDF>. Acesso em: 1 jun. 2010.

GARCIA, R. MOTTA, F. Relatório Setorial Final: Móveis residenciais de madeira. FINEP. 2007. Disponível em: <http://www.finep.gov.br/PortalDPP/ relatorio_setorial_final/relatorio_setorial_final_impressao.asp?lst_setor=303> Acesso em: 01 out. $201 \overline{2}$. 


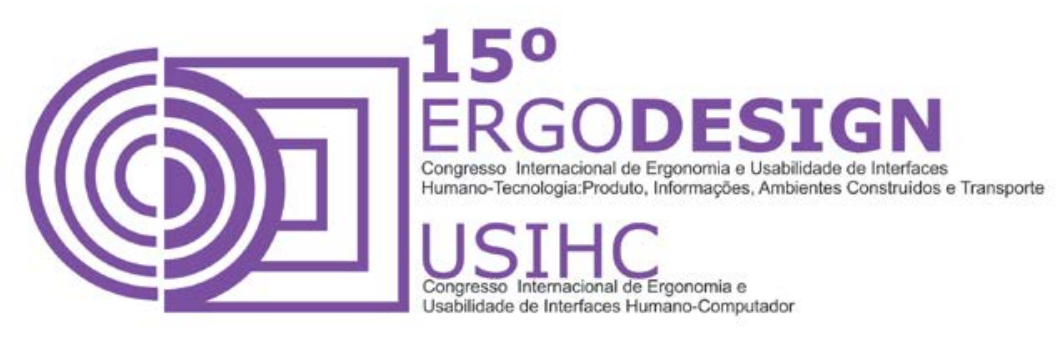

IIDA, I. Ergonomia: projeto e produção. São Paulo: Editora Edgard Blucher Ltda, 2005.

LANUTTI J. N. de L. Análise da percepção de uso de assentos ícones na história do design: uma abordagem do Design Ergonômico. In: ERGODESIGN, 9., 2009, Curitiba. Anais... Curitiba, 2009. p. 1-6.

MAFRA, J. R. D. VIDAL; M. C. R. Inovação e ergonomia: novos produtos, novos processos ou novos paradigmas. In: CONGRESSO LATINO-AMERICANO DE ERGONOMIA, CONGRESSO BRASILEIRO DE ERGONOMIA, SEMINÁRIO BRASILEIRO DE ACESSIBILIDADE INTEGRAL,7., 2002. Anais... Recife, 2002. p. 1-8. Disponível em: <http://www.ergonomia.ufrj.br/artigos/02_\%204.pdf>. Acesso em: 22 dez. 2014.

MENDONÇA, R. M. L. O; ALMEIDA Jr., G. Para uma ergonomia abrangente no mercado moveleiro. In: CONGRESSO INTERNACIONAL DE PESQUISA EM DESIGN, 4., 2007, Rio de Janeiro. Anais...2007. Disponível em: <http://www .anpedesign.org.br/artigos/pdf/Para\%20uma\%20Ergonomia\%20Abrangente\%20no\%20Mercad o\%20Moveleiro.pdf>. Acesso em: 24 nov. 2013.

MONT'ALVÃO, C. Ergodesign na vida cotidiana: sistemas de informação e produtos. In: WORKSHOP DE ANÁLISE ERGONÔMICA DO TRABALHO NA UFV, 3., 2007. Viçosa, MG. Anais... Viçosa, MG, 2007. 1 CD-ROM.

.PAOLIELLO,C. Análise biomecânica da estrutura de cadeiras de madeira. 2001. 205 f. Dissertação (Mestrado em Engenharia de Estruturas)-Escola de Engenharia, da Universidade Federal de Minas Gerais, Belo Horizonte, 2001.

RIBEIRO, F. M. Lar, simbólico lar: uma investigação sobre a compra de móveis de madeira, retilíneos e seriados, para residência, 2008. 131 f. Dissertação (Mestrado em Administração) Centro de Ciências Jurídicas e Econômicas, Universidade Federal do Espírito Santo, Vitória, ES, 2008.

SENAI. RS. CENTRO TECNOLÓGICO DO MOBILIÁRIO. Glossário mobiliário e madeira. Bento Gonçalves, 1994.173 p.

SERVIÇO BRASILEIRO DE APOIO ÀS MICRO E PEQUENAS EMPRESAS - SEBRAE. Móveis de cozinha. Estudos de Mercado Sebrae/ESPM. Relatório completo. 2008. 175 p. Disponível em: <http://www.biblioteca.sebrae .com.br/bds/BDS.nsf/B9CC0B872FB3A2378325753E005E974B/\$File/NT0003DB0A. pdf>.

Acesso em: 22 jan. 2014.

SERVIÇO BRASILEIRO DE APOIO ÀS MICRO E PEQUENAS EMPRESAS - SEBRAE. Móveis para dormitório. Estudos de Mercado Sebrae/ESPM. Relatório completo. 2008. 170 p. Disponível em: <http://www.biblioteca.sebrae .com.br/bds/BDS.nsf/B9CC0B872FB3A23783 25753E005E974B/\$File/NT0003DB0A.pdf>. Acesso em: 22 jan. 2010.

SILVA, C. E. S. da.; NETO, M. I. F; FILHO, J. L. F. da S. A integração da ergonomia no desenvolvimento de produtos. In. ENCONTRO NAC. DE ENGENHARIA DE PRODUÇÃO ENEGEP, 13., 1998, Niterói. Anais... Niterói, 1998. Disponível em: <www.iem.efei.br/sanches/Pesquisa/Artigos\%20publica dos/a19.PDF>. Acesso em: 22 jan. 2013.

SILVA,E. M. Avaliação da preferência de cadeiras para diferentes tipos de trabalhos de escritório. 2003. 265 f. Dissertação (Mestrado em engenharia de produção)-Escola de Engenharia da Universidade Federal do Rio Grande do Sul, Porto Alegre, RS, 2003. Disponível em: <http://www.lume.ufrgs.br/bitstre am/handle/10183/3483/000401423. pdf?sequence=1 $>$. Acesso em: 22 ago. 2010. 


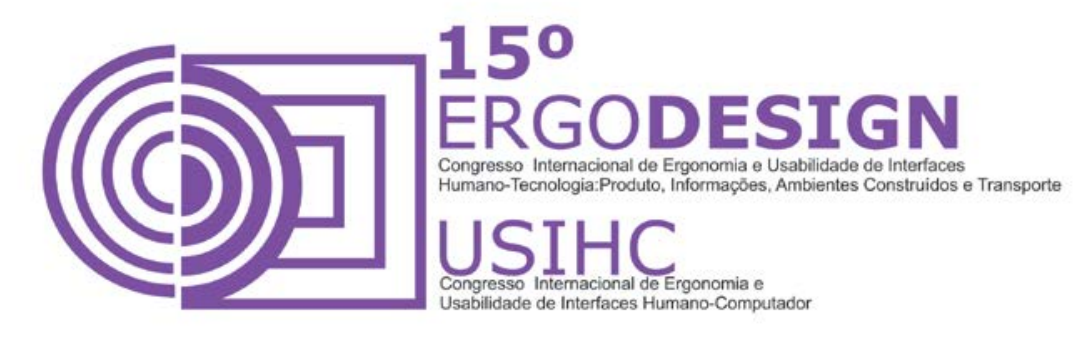

VILLAROUCO, V.; ANDRETO, L.F. M. Avaliando desempenho de espaços de trabalho sob o enfoque da ergonomia do ambiente construído. Produção, São Paulo, v. 18, n. 3, dez. 2008.

Disponível em: <http://www.scielo.br/scielo.php ?script=sci_arttext\&pid=S010365132008000300009\&lng=pt\&nrm=iso>. Acesso em: 25 jan. 2014.

\section{AGRADECIMENTOS}

Ao Centro Federal de Educação Tecnológica de Minas Gerais - CEFETMG, a Fundação de Amparo à Pesquisa do Estado de Minas Gerais - FAPEMIG, pelo apoio com bolsas e suporte financeiro a projetos $e$ ao Conselho Nacional de Desenvolvimento Científico e Tecnológico - CNPq. 